\title{
Two Carangid Fishes (Actinopterygii: Perciformes), Caranx heberi and Ulua mentalis, from Kagoshima: the First Records from Japan and Northernmost Records for the Species
}

\author{
Hiroyuki Motomura ${ }^{1}$, Seishi Kimura ${ }^{2}$ and Yuriko Haraguchi ${ }^{1}$ \\ ${ }^{1}$ The Kagoshima University Museum, 1-21-30 Korimoto, Kagoshima, 890-0065 Japan \\ E-mail:motomura@kaum.kagoshima-u.ac.jp \\ ${ }^{2}$ Fisheries Research Laboratory, Mie University, 4190-172 Wagu, Shima, Mie, 517-0703 Japan \\ E-mail:kimura-s@bio.mie-u.ac.jp
}

(Received 7 July 2007; Accepted 7 October 2007)

\begin{abstract}
Catches of two carangid fishes (Perciformes), Caranx heberi (Bennett, 1830) (two specimens: $251.5-260.0 \mathrm{~mm}$ fork length) and Ulua mentalis (Cuvier, 1833) (nine specimens: 203.6-244.0 mm), off Kasasa on the East China Sea side of Kagoshima Prefecture, Kyushu, Japan, represent the northernmost records of these Indo-West Pacific species. Caranx heberi has not previously been recorded north of the equator in the western Pacific, and the northernmost record of $U$. mentalis has been Taiwan. The Kagoshima specimens are described in detail and their biogeographic implications are discussed.

Key Words: Teleostei, Actinopterygii, Carangidae, Caranx heberi, Ulua mentalis, Japan, new records.
\end{abstract}

\section{Introduction}

In their catalog of Japanese fishes, Jordan et al. (1913) reviewed the previous literature related to Japanese fishes, including Temminck and Schlegel, Steindachner and Döderlein, and Hilgendorf, and listed 20 species of the family Carangidae from Japan (excepting the Ryukyu Islands), with the Japanese name for each. Wakiya (1924) later reviewed the carangoid fishes of Korea, Japan, and Taiwan in detail and recognized 74 species. Subsequently, Okada (1938) listed 66 carangid species from Japan (including the Ryukyu Islands) and Taiwan, 13 of which occurred only off Taiwan. Matsubara (1955) provided keys to 54 species of Carangidae from Japan, including the Ryukyu Islands.

More recently, Gushiken (1983) reviewed the carangid fishes of Japan and Taiwan, recognizing 57 species, and Senou (1993), who recognized 54 carangid species from Japan (including the Ryukyu Islands), illustrated and keyed all of the species. Thereafter, three carangid species, Alepes djedaba (Forsskål, 1775), Scomberoides commersonnianus Lacepède, 1801, and Trachinotus mookalee Cuvier, 1832, were recorded from Japan by Iwatsuki and Kimura (1996), Motomura et al. (1998), and Iwatsuki et al. (2000), respectively. Based on voucher specimens, Senou $(2000,2002)$ subsequently regarded 56 carangid species as occurring in Japanese waters, but failed to include $T$. mookalee. Accordingly, 57 carangid species in total are currently known from Japanese waters.

From November, 2006, to January, 2007, numerous carangid specimens with a 
rounded body, strong lower jaw, and long, numerous gill rakers were collected by trap nets set off Kasasa on the East China Sea side of Kagoshima Prefecture, Kyushu, southern Japan. Nine specimens were subsequently donated to the Kagoshima University Museum and identified as Ulua mentalis (Cuvier, 1833). In addition, two carangid specimens collected with $U$. mentalis and initially identified as Caranx papuensis Alleyne and Macleay, 1877 were subsequently shown to be $C$. heberi (Bennett, 1830). These specimens of $C$. heberi and $U$. mentalis represent the first confirmed records of these two species from Japan and are also the northernmost records for both thus far. The specimens are described below in detail and their biogeographic implications are discussed.

\section{Material and Methods}

Counts and measurements followed Hubbs and Lagler (1947) and Smith-Vaniz and Jelks (2006), with the exception of pectoral-fin ray counts, which here include the uppermost spine-like element. Scute counts for the straight portion of the lateral line include the scutes on the caudal-fin base. Standard and fork lengths are expressed as SL and FL, respectively. Specimens examined in this study have been deposited in the Field Museum of Natural History, USA (FMNH), the Fisheries Research Laboratory, Mie University, Japan (FRLM), and the Kagoshima University Museum, Japan (KAUM).

For comparison, the following specimens were examined. Caranx ignobilis (Forsskål, 1775): FMNH 59470 (formerly Carnegie Museum No. 7736), 163.2 mm SL (175.3 mm FL), Kii, Japan, studied by Wakiya (1924). Caranx papuensis: FRLM 10762, $227.5 \mathrm{~mm}$ SL $(248.0 \mathrm{~mm} \mathrm{FL})$, fish market at Yonabaru, Okinawa Island, Japan, 17 May 1990, coll. S. Kimura; KAUM-I. 1097, $206.8 \mathrm{~mm} \mathrm{SL} \mathrm{(220.1} \mathrm{mm} \mathrm{FL),} \mathrm{east} \mathrm{of}$ Sakinoyama, Kataura, Kasasa, Minami-satsuma, Kagoshima, Japan, 31 $25.44^{\prime} \mathrm{N}$, $130^{\circ} 11.49^{\prime} \mathrm{E}, 27 \mathrm{~m}$ depth, set net, 8 November 2006 , coll. M. Ito, collected with KAUMI. 1098 of $C$. heberi examined in this study.

\section{Taxonomy}

Caranx heberi (Bennett, 1830)

[New standard Japanese name: Itou-onihira-aji] (Figs 1A, 2A, Table 1)

Scomber heberi Bennett, 1830: unnumbered page, pl. 26 (type locality: south coast of Ceylon (Sri Lanka)).

Caranx sem Cuvier in Cuvier and Valenciennes, 1833: 105 (type locality: India). Caranx williamsi Smith, 1968: 180, pl. 38 (type locality: South Africa).

Material examined. KAUM-I. 1098, 1 specimen, $233.0 \mathrm{~mm}$ SL (251.5 mm FL), east of Sakinoyama, Kataura, Kasasa, Minami-satsuma, Kagoshima, Japan, $31^{\circ} 25.44^{\prime} \mathrm{N}, 130^{\circ} 11.49^{\prime} \mathrm{E}, 27 \mathrm{~m}$ depth, set net, 8 November 2006 , coll. M. Ito; KAUM-I. 1123, 1 specimen, $239.5 \mathrm{~mm}$ SL (260.0 mm FL), same data as KAUM-I. 1098, except for collection date, 9 November 2006. 

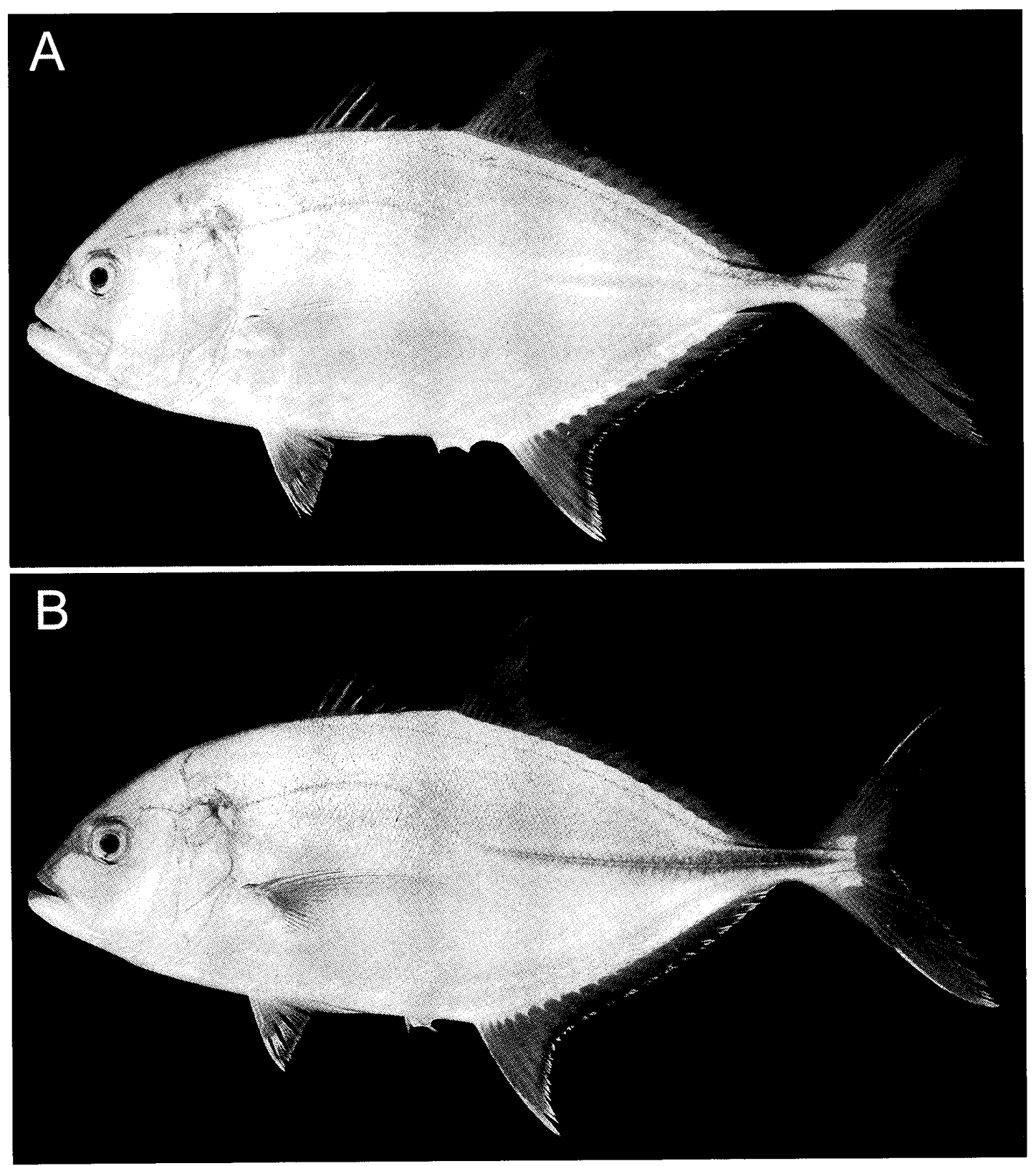

Fig. 1. A, Caranx heberi (Bennett, 1830), KAUM-I. 1098, 233.0 mm SL, Kasasa, Kagoshima, Japan; B, C. papuensis Alleyne and Macleay, 1877, KAUM-I. 1097, 206.8 mm SL.

Description of Japanese specimens. Counts and proportional measurements, the latter as percentages of FL, are given in Table 1.

Body and head moderately compressed, head width narrower than greatest body width. Body moderately deep, deepest at second dorsal-fin origin; dorsal profile more strongly convex than ventral profile. Head moderate, its length much greater than that of anal-fin lobe. Dorsal profile of snout in front of eye nearly straight. Mouth oblique, forming angle of about 25 degrees to horizontal axis of head and body. Horizontal line from anterodorsal corner of premaxilla passing through ventral margin of eye in lateral view. Posterior margin of maxilla extend- 
Table 1. Meristic and morphometric data for Japanese specimens of Caranx heberi.

\begin{tabular}{|c|c|c|c|}
\hline \multirow[b]{2}{*}{ KAUM-I. } & \multicolumn{3}{|c|}{ Caranx heberi } \\
\hline & 1098 & 1123 & Mean* \\
\hline D-fin rays & VIII-I, 20 & VIII-I, 19 & VIII-I, 20 \\
\hline A-fin rays & II-I, 15 & II-I, 15 & II-I, 15 \\
\hline $\mathrm{P}_{1}$-fin rays & 21 & 21 & 21 \\
\hline $\mathrm{P}_{2}$-fin rays & $\mathrm{I}, 5$ & $\mathrm{I}, 5$ & I, 5 \\
\hline Gill rakers & $7+18$ & $7+17$ & $7+18$ \\
\hline Scales in curved portion of lateral line & 59 & 55 & 57 \\
\hline Scales in straight portion of lateral line & 3 & 5 & 4 \\
\hline Scutes in straight portion of lateral line & 35 & 31 & 33 \\
\hline Standard L (SL, mm) & 233.0 & 239.5 & \\
\hline Fork L $(\mathrm{FL}, \mathrm{mm})$ & 251.5 & 260.0 & \\
\hline \multicolumn{4}{|l|}{$\% \mathrm{FL}$} \\
\hline Body depth & 33.5 & 33.0 & 33.2 \\
\hline Head L & 26.9 & 27.0 & 26.9 \\
\hline Snout L & 7.5 & 7.7 & 7.6 \\
\hline Upper-jaw L & 11.6 & 12.0 & 11.8 \\
\hline Orbit diameter & 5.9 & 6.1 & 6.0 \\
\hline Postorbital head L & 14.5 & 14.4 & 14.4 \\
\hline Interorbital width & 6.4 & 6.8 & 6.6 \\
\hline Snout to 1st D-fin origin & 36.9 & 37.4 & 37.2 \\
\hline Snout to 2nd D-fin origin & 53.1 & 53.6 & 53.3 \\
\hline Snout to $\mathrm{P}_{2}$-fin origin & 30.0 & 29.5 & 29.8 \\
\hline Snout to 1st A-fin spine & 48.1 & 47.9 & 48.0 \\
\hline D-fin base $\mathrm{L}$ & 51.9 & 51.5 & 51.7 \\
\hline A-fin base $L$ & 37.3 & 37.5 & 37.4 \\
\hline 1st D-fin origin to 2nd D-fin origin & 17.4 & 17.9 & 17.6 \\
\hline Longest D-fin spine L & 11.1 & - & 11.1 \\
\hline D-fin lobe L & 17.7 & 17.4 & 17.6 \\
\hline A-fin lobe $L$ & 16.9 & 16.8 & 16.9 \\
\hline$P_{1}$-fin L & 31.9 & 31.5 & 31.7 \\
\hline $\mathrm{P}_{2}$-fin L & 13.5 & 13.3 & 13.4 \\
\hline Upper C-fin lobe L & 25.3 & 24.5 & 24.9 \\
\hline Lower C-fin lobe L & 24.8 & 24.4 & 24.6 \\
\hline C-peduncle L & 11.6 & 11.8 & 11.7 \\
\hline C-peduncle depth & 3.4 & 3.4 & 3.4 \\
\hline $\mathrm{L}$ of curved portion of lateral line & 36.7 & 34.0 & 35.4 \\
\hline $\mathrm{L}$ of straight portion of lateral line & 32.7 & 34.3 & 33.5 \\
\hline
\end{tabular}

Abbreviations: A, anal; $\mathrm{C}$, caudal; $\mathrm{D}$, dorsal; $\mathrm{L}$, length; $\mathrm{P}_{1}$, pectoral; $\mathrm{P}_{2}$, pelvic.

* Mean values for meristic data are rounded off to whole numbers.

ing slightly beyond vertical line drawn through posterior margin of pupil; posterior end of maxilla slightly concave, slanted anteroventrally. Lower jaw well developed, not projecting beyond upper jaw; height of dentary subequal to pupil diameter. Upper jaw with two rows of teeth, including outer row of strong canines (all widely separated from each other) and inner row of villiform teeth; vomer and palatines with villiform teeth; tongue without teeth. Anterior nostril slightly 
larger than posterior nostril; both nostrils elliptical. Fleshy adipose eyelid well developed, covering eye anteriorly and posteriorly; pupil completely exposed. Snout length greater than orbit diameter. Posterodorsal margin of opercular membrane smooth. Cleithrum margin smooth. Gill rakers seven on upper limb, 17 or 18 on lower limb of first gill arch, total rakers 24 or 25; longest raker on first gill arch subequal in length to longest gill filament, slightly greater than orbit diameter; rakers on anteroventral portion of first gill arch not projecting into mouth along side of tongue.

First dorsal fin with eight spines; fin origin posterior to pelvic-fin origin; longest spine slightly greater than orbit diameter. Second dorsal fin with one spine and 19 or 20 soft rays, its lobe shorter than head. Pelvic-fin origin located posterior to base of uppermost pectoral-fin ray. Pelvic-fin length at most slightly greater than length of upper jaw; posterior tip of depressed pelvic fin not reaching base of first detached anal-fin spine. No median groove on ventral surface of body behind pelvic-fin bases. Anus located at posterior tip of second soft ray of depressed pelvic fin. Anal fin with two detached spines followed by one spine and 15 soft rays; its lobe shorter than that of second dorsal fin. Second dorsal and anal fins without finlets. Pectoral fin with 21 rays, upper two unbranched, remaining rays branched; fin relatively long, its posterior tip reaching to vertical line drawn through base of fourth anal-fin soft ray. Caudal fin deeply forked.

Anterior portion of lateral line moderately curved, with 55-59 pored scales but lacking scutes; posterior portion of lateral line straight, with three to five scales followed by 31-35 scutes; junction of curved and straight portions generally above base of second anal-fin soft ray. Posterior end of dorsal accessory lateral line not reaching to vertical line drawn through first dorsal-fin origin. No scales on anteroventral surface of body, except for small patch of pre-pelvic scales in KAUM-I. 1098 (these absent in KAUM-I. 1123).

Color when fresh. Based on color photographs taken of the two present specimens when fresh. Head and body bluish-green dorsally, becoming silvery ventrally, without spots, blotches, bands, or stripes. Lips and maxilla faintly yellow. First dorsal fin grayish. Second dorsal fin grayish, faintly yellow basally. Pelvic fin yellowish-white. Anal fin yellow, with whitish margin. Pectoral fin semi-transparent, yellowish basally. Upper lobe of caudal fin black; lower lobe yellow with black pigment spots scattered centrally. Scutes semi-transparent.

Color of preserved specimens. Head and body bluish-gray dorsally, becoming silvery-white ventrally, without spots, blotches, bands, or stripes. Inside of mouth whitish. First dorsal-fin membranes semi-transparent with tiny, scattered, grayish pigment spots. Second dorsal fin yellowish-white basally, with narrow black distal margin. Pelvic and anal fins yellowish-white. Inner side of pectoral-fin base dense black dorsally, yellowish-white ventrally; pectoral fin yellowish, semi-transparent. Caudal fin blackish, especially upper part of upper lobe. Scutes semi-transparent.

Remarks. The specimens were identified as belonging to the genus Caranx, being characterized by a more convex dorsal than ventral profile; $20-31$ gill rakers in total on the first gill arch; an outer series of canines and an inner band of fine teeth on the upper jaw; teeth present on the vomer and palatines; a smooth cleithrum margin, without papillae; dorsal- and anal-fin soft rays not produced as filaments; second dorsal and anal fins without finlets; presence of pelvic fins, these not being positioned distinctly anterior to a vertical line drawn through the pectoral- 
fin base; non-embedded body scales; and scutes present only on the straight portion of the lateral line (Smith-Vaniz 1999). Eight species of Caranx occur in the western Pacific according to Smith-Vaniz (1999), and the characters of our specimens agree with those given for $C$. heberi by that author. Caranx heberi can be distinguished from all western Pacific congeners by total gill raker count (25-27, rarely 24), the total of 34-38 soft rays of the dorsal and anal fins, presence of scales covering the pectoral-fin base, absence of small black spots on the upper end of the opercle, and absence of both bluish coloration of the fins and dense black pigmentation of the scutes.

In its subadult stage, Caranx heberi resembles a sympatric species, $C$. papuensis, in overall appearance and fin color pattern, but it differs from the latter in having 34-37 (rarely 38) soft rays in total in the dorsal and anal fins (vs. 38-41, rarely 37, in C. papuensis) and the posterior margin of the maxilla extending slightly beyond a vertical line drawn through the posterior margin of the pupil (Fig. 2A), versus not reaching so far posteriorly (Fig. 2B).

Smith-Vaniz (1999) mentioned that the squamation on the anteroventral surface of the body in $C$. heberi varies from completely scaled to naked, although typically a patch of pre-pelvic scales is present. Of the present specimens, KAUM-I. 1098 had a small patch of pre-pelvic scales, whereas KAUM-I. 1123 lacked such a scale patch.

Smith-Vaniz (1986) regarded Caranx sem Cuvier, 1833 as a valid species, namely a senior synonym of $C$. williamsi Smith, 1968. Subsequently, Pethiyagoda et al. (1994) considered Scomber heberi Bennett, 1830 to be a senior synonym of C. sem. Currently, $C$. sem and $C$. williamsi are both regarded as junior synonyms of $S$. heberi (see Randall 1995; Smith-Vaniz 1999).

Smith-Vaniz (1986) included "Okinawa" in the distributional range of Caranx heberi (as C. sem) and Fricke (1999) reported the distribution of $C$. heberi as "north to Ryukyu Islands"; however, no references or specimens substantiating Japanese records of the species were given in either of these works. Subsequently, SmithVaniz (1999) regarded the range of $C$. heberi as including Indonesia, the Arafura Sea, Ambon, New Guinea, and New Britain in the western Pacific. Gushiken (1983)
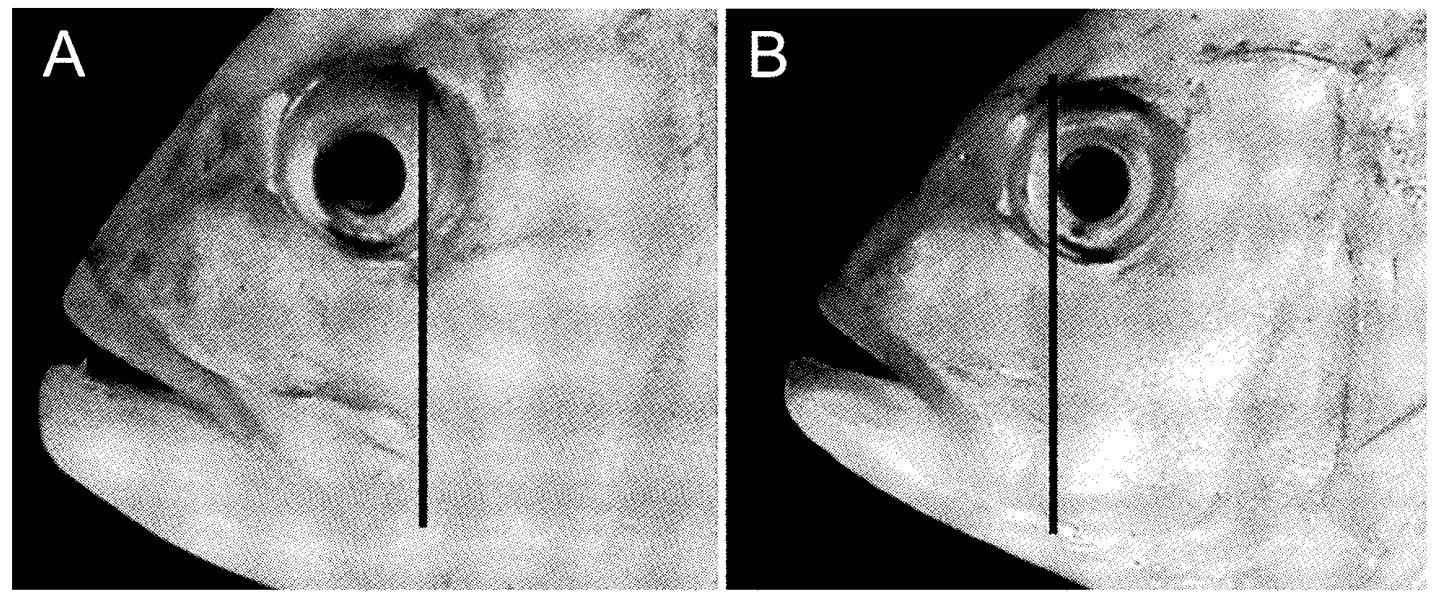

Fig. 2. Anterior parts of head. A, Caranx heberi (Bennett, 1830), KAUM-I. 1123, $239.5 \mathrm{~mm}$ SL ; B, C. papuensis Alleyne and Macleay, 1877, KAUM-I. 1097, 206.8 mm SL. The black line in each indicates the position of the posterior edge of the maxilla relative to the pupil. 
and Lin and Shao (1999) reviewed carangid fishes from Japan and Taiwan, respectively, but did not include $C$. heberi (nor either C. sem or C. williamsi). In addition, the species has not been recorded from the Hawaiian Islands (e.g., Randall 2007). In fact, no reliable records of $C$. heberi from north of the equator in the western $\mathrm{Pa}$ cific have been published. The present two specimens represent the first records of C. heberi from Japan and also the northernmost records of the species.

Wakiya (1924) gave a description of Caranx bucculentus Alleyne and Macleay, 1876 on the basis of a single specimen from Kii, Japan. Although the description agrees with C. heberi (Smith-Vaniz, pers. comm.), Gushiken (1983) considered that Wakiya's (1924) C. bucculentus was $C$. ignobilis. Examination of Wakiya's specimen during this study also showed it to be $C$. ignobilis since it has 22 total gill rakers on the first gill arch (vs. 25-27, rarely 24, in C. heberi) and 26 scutes along the straight portion of the lateral line (vs. 30-40).

Murakami et al. (2007) reported a single hybrid specimen of $C$. melampygus $\mathrm{Cu}$ vier, $1833 \times$ C. sexfasciatus Quoy and Gaimard, 1825 from O'ahu, Hawaiian Islands. The specimen (BPBM 39582, $261 \mathrm{~mm} \mathrm{FL}$; fig. 3A) is similar to our specimens of $C$. heberi (251.5-260.0 mm FL) in overall body appearance, but differs in having a total of 40 soft rays in the dorsal and anal fins (vs. 34-35 in our specimens of $C$. heberi) and blackish pectoral, pelvic, and anal fins as well as lower caudal-fin lobe (vs. yellowish fins).

The new standard Japanese name, Itou-onihira-aji, is proposed here for $C$. heberi in honor of Mr. Masahide Ito (Kasasa, Kagoshima, Japan), who made available to us all of the specimens of this species examined in this study. Incidentally, onihira-aji is the standard Japanese name of $C$. papuensis.

Ulua mentalis (Cuvier, 1833)

[Standard Japanese name: Hishi-kaiwari]

(Fig. 3, Table 2)

Caranx mentalis Cuvier in Cuvier and Valenciennes, 1833: 124 (type locality: Massawa, Eritrea, Red Sea).

Leioglossus carangoides Bleeker, 1851: 367 (type locality: Indonesia).

Caranx mandibularis Macleay, 1882: 356 (type locality: New Guinea).

Ulua richardsoni Jordan and Snyder, 1908: 39, pl. 53 (type locality: Taiwan).

Material examined. KAUM-I. 1120-1122, 3 specimens, $187.5-217.5 \mathrm{~mm}$ SL (203.6-235.0 mm FL), east of Sakinoyama, Kataura, Kasasa, Minami-satsuma, Kagoshima, Japan, $31^{\circ} 25.44^{\prime} \mathrm{N}, 130^{\circ} 11.49^{\prime} \mathrm{E}, 27 \mathrm{~m}$ depth, set net, 9 November 2006 , coll. M. Ito; KAUM-I. 1505-1507, 3 specimens, 212.5-225.5 mm SL (232.5-244.0 mm FL), south of Nomamisaki, Kasasa, Minami-satsuma, Kagoshima, Japan, $31^{\circ}$ $24.49^{\prime} \mathrm{N}, 130^{\circ} 07.00^{\prime} \mathrm{E}, 27 \mathrm{~m}$ depth, set net, 4 January 2007, coll. K. Funakawa; KAUMI. 1508, 1509, 2 specimens, 216.8, 222.0 mm SL (232.0, 242.0 mm FL), off Kouzaki-yama, Kasasa, Minami-satsuma, Kagoshima, Japan, $31^{\circ} 26.00^{\prime} \mathrm{N}, 130^{\circ} 10.05^{\prime} \mathrm{E}, 36 \mathrm{~m}$ depth, set net, 27 November 2006, coll. K. Nakahata; KAUM-I. 1635, 1 specimen, $202.5 \mathrm{~mm}$ SL (219.5 mm FL), northeast of Matsu Island, Kasasa, Minami-satsuma, Kagoshima, Japan, $31^{\circ} 25.06^{\prime} \mathrm{N}, 130^{\circ} 12.32^{\prime} \mathrm{E}, 20 \mathrm{~m}$ depth, set net, 18 December 2006 , coll. M. Ito.

Description of Japanese specimens. Counts and proportional measure- 


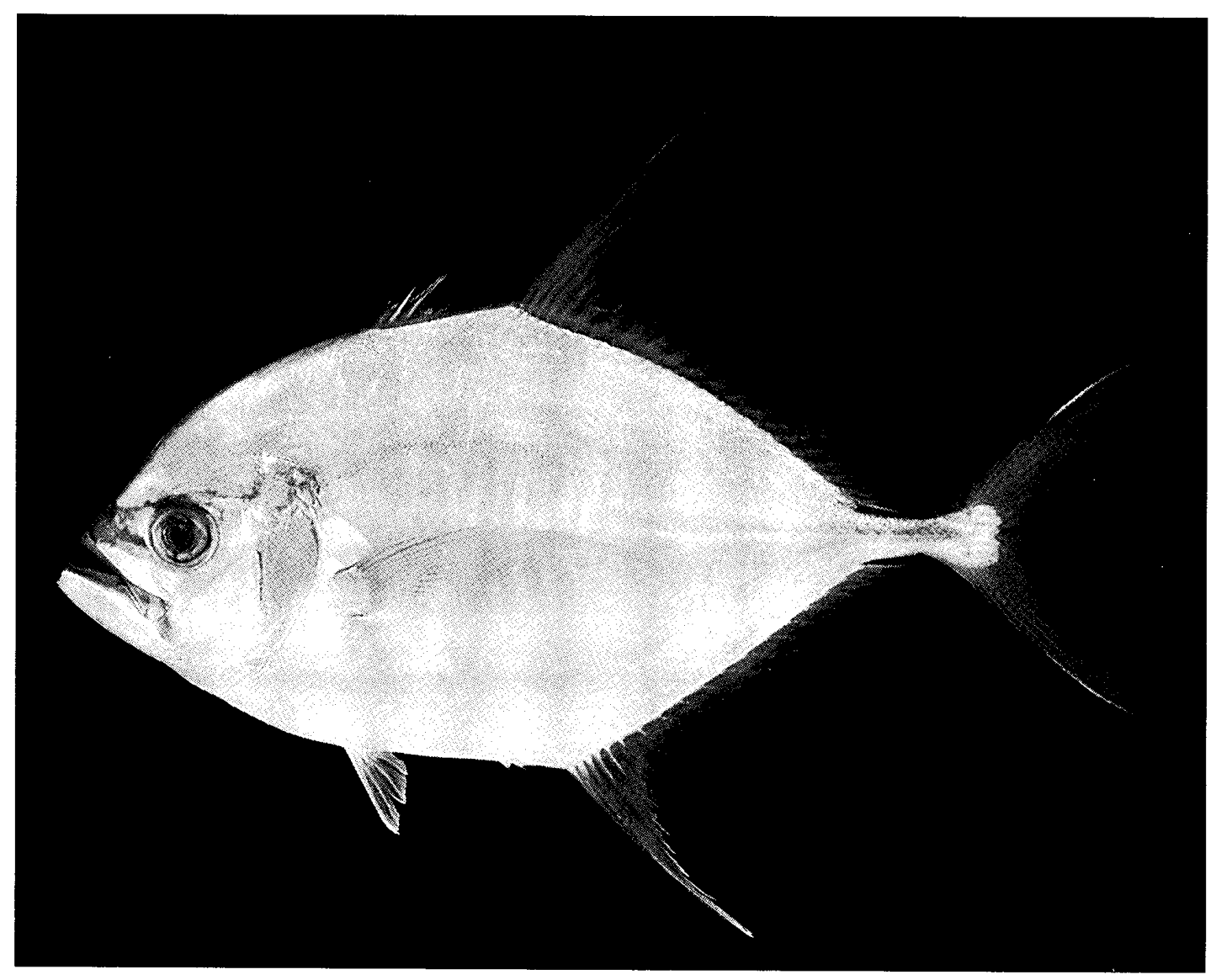

Fig. 3. Ulua mentalis (Cuvier, 1833), KAUM-I. 1120, 187.5 mm SL, Kasasa, Kagoshima, Japan.

ments, as percentages of FL, are given in Table 2.

Body and head strongly compressed, head width narrower than greatest body width. Body deep, deepest at second dorsal-fin origin; dorsal profile more strongly convex than ventral profile. Head moderate, its length slightly shorter than that of anal-fin lobe. Dorsal profile of snout in front of eye strongly concave. Mouth oblique, forming angle of about 30 degrees to horizontal axis of head and body. Horizontal line drawn from anterodorsal corner of premaxilla passing through middle of eye in lateral view. Posterior margin of maxilla extending slightly beyond vertical line drawn through anterior margin of pupil; posterior end of maxilla almost straight (not convex or concave), slanted anteroventrally. Lower jaw well developed, projecting slightly beyond upper jaw; height of dentary greater than pupil diameter. Both jaws with row of small teeth; vomer and palatines with villiform teeth; tongue without teeth. Anterior nostril larger than posterior nostril; both nostrils elliptical. Fleshy adipose eyelid poorly developed, covering only outer margin of eye; pupil completely exposed. Snout length subequal to eye diameter. Posterodorsal margin of opercular membrane smooth. Cleithrum margin smooth. Gill rakers 25-29 on upper limb, 53-57 on lower limb of first gill arch, total rakers 79-85; longest raker on first gill arch subequal in length to longest gill filament, slightly greater than orbit diameter; rakers on anteroventral portion of first gill arch projecting into mouth along side of tongue. 


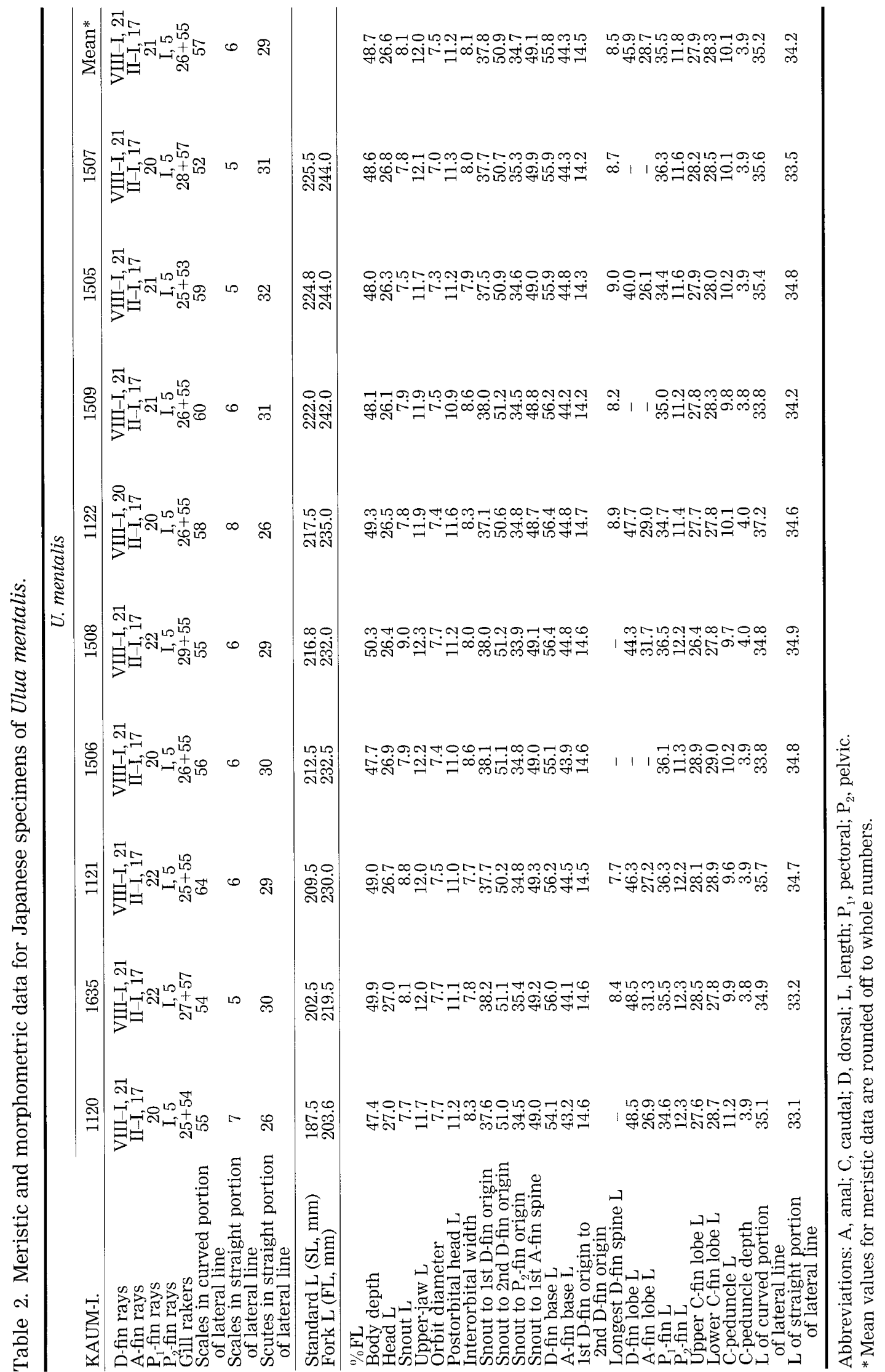


First dorsal fin with eight spines; fin origin just above pelvic-fin origin; length of longest spine slightly greater than orbit diameter. Second dorsal fin with one spine and 20 or 21 soft rays; second dorsal-fin lobe longer than head. Pelvic-fin origin located posterior to uppermost pectoral-fin ray base. Pelvic-fin length at most subequal to upper-jaw length; posterior tip of depressed pelvic fin not reaching base of first detached anal-fin spine. Median groove on ventral surface of body behind pelvic-fin bases. Anus located at posterior tip of shortest (fifth) soft ray of depressed pelvic fin. Anal fin with two detached spines followed by one spine and 17 soft rays; anal-fin lobe shorter than second dorsal-fin lobe. Second dorsal and anal fins without finlets. Pectoral fin with 20-22 rays, upper two unbranched, remaining rays branched; fin relatively long, its posterior tip reaching to vertical line drawn through middle of anal-fin base. Caudal fin deeply forked. Deep median groove on ventral surface of body behind pelvic fins, not accommodating two detached anterior anal-fin spines.

Anterior portion of lateral line moderately curved, with 52-64 pored scales but lacking scutes; posterior portion of lateral line straight, with five to eight scales followed by 26-32 scutes; junction of curved and straight portions generally above base of first anal-fin soft ray. Posterior end of dorsal accessory lateral line not reaching to vertical line drawn through first dorsal-fin origin. No scales on area bounded by pectoral-fin base, gill opening, and pelvic-fin base, including anteroventral surface of body.

Color when fresh. Based on color photographs taken of the present nine specimens when fresh. Head and body bluish-green dorsally, becoming silvery ventrally, without spots, blotches, bands, or stripes. Snout region, lips, and maxilla blackish. Dorsal fins grayish. Pelvic and anal fins whitish with scattered black pigment spots. Pectoral fin semi-transparent. Caudal fin grayish basally, black distally. Scutes semi-transparent.

Color of preserved specimens. Head and body bluish-gray dorsally, becoming silvery white ventrally, without spots, blotches, bands, or stripes. Inside of mouth whitish, with black pigment spots scattered on tongue; lips blackish. First dorsalfin membranes semi-transparent with blackish pigment spots scattered anteriorly. Second dorsal-fin lobe grayish basally, blackish distally; remaining parts of second dorsal fin whitish, with blackish band along each soft ray anteriorly. Pelvic fin whitish basally, blackish distally. Anal-fin lobe grayish; remaining parts of anal fin whitish, with blackish blotch anterior to each soft ray. Inner pectoral-fin base entirely black; pectoral fin whitish, semi-transparent. Caudal fin blackish, especially distal margin and tips of upper and lower lobes. Scutes semi-transparent.

Remarks. The specimens examined here belong to the genus Ulua Jordan and Snyder, 1908, which is characterized by a moderately developed adipose eyelid covering only the outer margin of the eye; snout length subequal to the orbit diameter; upper jaw with a row of teeth; vomer and palatines with teeth; cleithrum margin smooth, lacking papillae; gill rakers on the first gill arch numbering 54-86, with the anteroventral ones projecting into mouth along side of the tongue; second dorsal and anal fins without finlets; pectoral fins longer than the head; the pelvic-fin origin being positioned posterior to a vertical line drawn through the base of the uppermost pectoral-fin ray; scutes along the posterior straight portion of the lateral line; the posterior end of the dorsal accessory lateral line not reaching a vertical line drawn through the first dorsal-fin origin; exposed body scales; and the 
breast being naked ventrally (Smith-Vaniz 1999). This Indo-West Pacific genus includes two species, $U$. aurochs (Ogilby, 1915) and $U$. mentalis. Our specimens are well consistent with the descriptions of $U$. mentalis given by Lin and Shao (1999) and Smith-Vaniz $(1986,1999)$, with the exception of some counts; e.g., 5-8 scales followed by 26-32 scutes on the straight portion of the lateral line versus 3-6 scales and 28-36 scutes in Lin and Shao (1999) and 0-5 scales and 26-38 scutes in SmithVaniz (1986, 1999). The counts given by Lin and Shao (1999) were based on only two specimens from Taiwan [specimen number was not stated by Smith-Vaniz (1986, 1999)], so these small differences may simply reflect the limited number of specimens available.

The present specimens differ from Ulua aurochs in having 79-85 total gill rakers on the first gill arch, comprising 25-29 on the upper limb and 53-57 on the lower limb (vs. 54-61 total rakers, 16-21 on the upper limb and 37-41 on the lower limb; Smith-Vaniz 1999), and the tongue without teeth (vs. having a central band of villiform teeth; Smith-Vaniz 1999). Ulua mentalis can also be readily distinguished from all other species of Carangidae by the presence of more than 51 gill rakers on the lower limb of the first gill arch.

Ulua mentalis has to date been recorded from Madagascar and Mozambique north and east to the Red Sea, the Persian Gulf and Sri Lanka in the Indian Ocean (Randall 1995; Smith-Vaniz 1999), and from Taiwan to northern Australia, including coastal waters of Southeast Asia, in the western Pacific (Smith-Vaniz 1999). The present specimens represent the first records of $U$. mentalis from Japan and also the northernmost records of the species.

Leioglossus carangoides, Caranx mandibularis, and Ulua richardsoni have been regarded as junior synonyms of C. mentalis by Eschmeyer (1998), SmithVaniz (1986), and Lin and Shao (1999), respectively.

Japanese names, Urua-aji and Hishi-kaiwari, were proposed for Ulua richardsoni by Okada (1938) and Matsubara (1955), respectively. We propose that the latter remain as the standard Japanese name for $U$. mentalis because "urua" (="ulua") is a common name used by sport anglers for all large Caranx individuals and its use here as a standard name is thus inappropriate. The Japanese name for the genus Ulua is Hishi-kaiwari zoku (Matsubara 1955).

\section{Biogeographic Implications}

During the three months between 14 October 2006 and 4 January 2007, numerous individuals of uncommon carangid fishes were collected off Kasasa, Kagoshima, Japan, including Caranx heberi, Ulua mentalis, Atule mate (Cuvier, 1833), and Caranx tille Cuvier, 1833. Although only three specimens of $A$. mate have previously been reported from Japanese waters (Suzuki 1962; Yoshino and Yoshigou 2003; Miyahara et al. 2006), an additional 14 specimens were collected from Kasasa during the period noted above (specimens listed in Ito et al. 2007). Caranx tille is also of rare occurrence in Japan, previously known only from Yamaguchi Prefecture (Suzuki 1962, reported as C. hippos) and Okinawa Island (Gushiken 1983). However, 11 specimens were collected from Kasasa on 8 and 9 November 2006 (Kita 2007). Although numerous specimens of $C$. heberi, C. tille, and $U$. mentalis were collected, all were young, measuring $233.0-239.5 \mathrm{~mm}, 170.6-185.8 \mathrm{~mm}$, 
and 187.5-225.5 mm SL, respectively (each species at maturity attains at least 600 $\mathrm{mm}$; Smith-Vaniz 1999). This suggests that large schools of young individuals of these species were accidentally transported by the Kuroshio Current to Kagoshima from Taiwan or China; it is unlikely that any of the species reproduces around Japan.

\section{Acknowledgments}

We are especially grateful to M. Ito (Kagoshima, Japan) for his donation of all specimens of $C$. heberi and $U$. mentalis examined in this study, and to $M$. Takayama, M. Matsunuma, G. Ogihara, and M. Meguro (Kagoshima, Japan) for their curatorial assistance. We are greatly appreciative to W. Smith-Vaniz (Florida Caribbean Science Center, USA) for valuable comments on the manuscript and P. Willink and K. Swagel (FMNH) for providing data and images of the specimen of $C$. ignobilis. This study was supported in part by a Grant-in-Aid for Scientific Research (A) from the Japan Society for the Promotion of Science, Tokyo, Japan (19208019) and a Grant-in-Aid for Young Scientists (B) from the Ministry of Education, Science, Sports and Culture, Japan (19770067).

\section{References}

Bennett, J. W. 1830. A Selection from the Most Remarkable and Interesting Fishes Found on the Coast of Ceylon from Drawings Made in the Southern Part of That Island, from the Living Specimens. Longman, Rees, Brown, and Green, London, 13 pp. (unnumbered), pls 16-30.

Bleeker, P. 1851. Over eenige nieuwe geslachten en soorten van Makreelachtige visschen van den Indischen Archipel. Natuurkundig Tijdschrift voor Nederlandsch-Indië 1: 341-372.

Cuvier, G. and Valenciennes, A. 1833. Histoire Naturelle des Poissons. Vol. 9. Levrault, Paris, $512 \mathrm{pp}$.

Eschmeyer, W. N. (ed.) 1998. Catalog of Fishes. Vol. 1. Introductory Materials, Species of Fishes, $A-L$. California Academy of Sciences, San Francisco, 958 pp.

Fricke, R. 1999. Fishes of the Mascarene Islands (Réunion, Mauritius, Rodriguez). An Annotated Checklist with Descriptions of New Species. Koeltz Scientific Books, Köenigstein, viii $+759 \mathrm{pp}$.

Gushiken, S. 1983. Revision of the carangid fishes of Japan. Galaxea 2: 135-264.

Hubbs, C. L. and Lagler, K. F. 1947. Fishes of the Great Lakes Region. Cranbrook Institure of Science Bulletin 26: i-xi, 1-186.

Ito, M., Takayama, M., Haraguchi, Y., Matsunuma, M. and Motomura, H. 2007. A large number of a rare fish, Atule mate (Teleostei: Perciformes: Carangidae), collected from Kagoshima, Japan. Nankiseibutsu 49: 117-118. [In Japanese]

Iwatsuki, Y. and Kimura, S. 1996. First record of the carangid fish, Alepes djedaba (Forsskål) from Japanese waters. Ichthyological Research 43: 182-185.

Iwatsuki, Y., Motomura, H., Toda, M., Yoshino, T. and Kimura, S. 2000. First record of a carangid fish, Trachinotus mookalee, from Japan (Perciformes: Carangidae). Japanese Journal of Ichthyology 47: 135-138. [In Japanese]

Jordan, D. S. and Snyder, J. O. 1908. Descriptions of three new species of carangoid fishes from Formosa. Memoirs of the Carnegie Museum 4: 37-40. 
Jordan, D. S., Tanaka, S. and Snyder, J. O. 1913. A catalogue of the fishes of Japan. Journal of the College of Science, Tokyo Imperial University 33: 1-497.

Kita, N. 2007. Minami-gingame-aji. Caranx tille Cuvier, 1833. The Kagoshima University Museum News Letter 16: 13. [In Japanese]

Lin, P.-L. and Shao, K.-T. 1999. A review of the carangid fishes (family Carangidae) from Taiwan with descriptions of four new records. Zoological Studies 38: 33-68.

Macleay, W. 1882. Contribution to a knowledge of the fishes of New Guinea. No. 2. Proceedings of the Linnaean Society of New South Wales 7: 351-366.

Matsubara, K. 1955. Fish Morphology and Hierarchy. Part 1. Ishizaki-shoten, Tokyo, xi+789 pp. [In Japanese]

Miyahara, H., Ito, M. and Yabe, M. 2006. Record of the yellowtail scad, Atule mate (Perciformes: Carangidae), from Kagoshima Prefecture, Japan. Bulletin of the Biogeographical Society of Japan 61: 81-84. [In Japanese]

Motomura, H., Iwatsuki, Y., Yoshino, T., Kimura, S. and Inamura, O. 1998. A record of a carangid fish, Scomberoides commersonnianus, from Japan (Perciformes: Carangidae). Japanese Journal of Ichthyology 45: 101-105. [In Japanese]

Murakami, K., James, S. A., Randall, J. E. and Suzumoto, A. Y. 2007. Two hybrids of carangid fishes of the genus Caranx, C. ignobilis $\times C$. melampygus and C. melampygus $\times C$. sexfasciatus, from the Hawaiian Islands. Zoological Studies 46: 186-193.

Okada, Y. 1938. A Catalogue of Vertebrates of Japan. Maruzen, Tokyo, iv+412 pp.

Pethiyagoda, R., Raheem, I. and Russell, B. C. 1994. J. W. Bennett, his fish names and the dates of publication of "Fishes of Ceylon". Journal of South Asian Natural History 1: 35-48.

Randall, J. E. 1995. Coastal Fishes of Oman. University of Hawai'i Press, Honolulu, xiii+439 pp.

Randall, J. E. 2007. Reef and Shore Fishes of the Hawaiian Islands. University of Hawai'i Sea Grant College Program, Honolulu, xiv +546 pp.

Senou, H. 1993. Carangidae. Jacks. Pp. 690-705, 1318-1320. In: Nakabo, T. (Ed.) Fishes of Japan with Pictorial Keys to the Species. Tokai University Press, Tokyo. [In Japanese]

Senou, H. 2000. Carangidae. Jacks. Pp. 796 808, 1554-1557. In: Nakabo, T. (Ed.) Fishes of Japan with Pictorial Keys to the Species. Tokai University Press, Tokyo. [In Japanese]

Senou, H. 2002. Carangidae. Jacks. Pp. 791-808, 1547-1549. In: Nakabo, T. (Ed.) Fishes of Japan with Pictorial Keys to the Species. English Edition. Tokai University Press, Tokyo.

Smith, J. L. B. 1968. Studies in carangid fishes No. 4. The identity of Scomber sansun Forsskål, 1775. Rhodes University Department of Ichthyology Occasional Paper 15: 173-184.

Smith-Vaniz, W. F. 1986. Family no. 210: Carangidae. Pp. 638-661. In: Smith, M. M. and Heemstra, P. C. (Eds) Smith's Sea Fishes. J. L. B. Smith Institute of Ichthyology, Grahamstown.

Smith-Vaniz, W. F. 1999. Carangidae. Jacks and scads (also trevallies, queenfishes, runners, amberjacks, pilotfishes, pampanos, etc.). Pp. 2659-2756. In: Carpenter, K. E. and Niem, V. H. (Eds) FAO Species Identification Guide for Fishery Purposes. The Living Marine Resources of the Western Central Pacific. Vol. 4. Bony Fishes Part 2 (Mugilidae to Carangidae). FAO, Rome.

Smith-Vaniz, W. F. and Jelks, H. L. 2006. Australian trevallies of the genus Pseudocaranx (Teleostei: Carangidae), with description of a new species from Western Australia. Memoirs of Museum Victoria 63: 97-106.

Suzuki, K. 1962. Anatomical and taxonomical studies on the carangid fishes of Japan. Report of Faculty of Fisheries, Prefectural University of Mie 4: 43-232.

Wakiya, Y. 1924. The carangoid fishes of Japan. Annals of the Carnegie Museum 15: 139-292.

Yoshino, T. and Yoshigou, H. 2003. Second record of Atule mate (Pisces, Carangidae) from Japan. I. O. P. Diving News 14: 2-4. [In Japanese] 